On one piece of rock there are at least thirieen of the markings visible, and the rings or grooves round the central depression vary in numbers from one to six. Mr. Joseph Lund, of Overdale, Ilkley, who most politely guided me to the stones in question, also showed me, in his own garden, a large block of grit, bearing some of these markings, from cach of which is a district channel cut to the edge of the rock. There bave been many theories as to the significance of these markings. Has their use been yct ascertaincd ?

Jiest IIartlepool, May I5

R. Morton Middetox, Jun.

\section{A Double Egg}

ThE other day on opening an egg, certainly a fine one, I found inside another perfect egg, so far as shell and the white part are concerned, but with only a faint streak of yellow for yolk. Double yolks are common, but I never saw, or rearl of, a perfectly formed shell inside an ordinary one before. If you think it worth notice, I send it for that purpose.

Stafford, May I4

\section{COMPARATIVE ANATOMY OF MAN'}

II.

$\mathrm{W}$

ITH regard to the cranial characters of the Americans the same difference of statement is met with as in respect to their external appearance. Morton's assertion of the gencral sameness in the skulls from all parts of the continent has been contested by others. But the controversies relating to this subject have nearly all turned upon one character alone, that is, the relative breadth of the cranium compared to its length, to the neglect of many others probably of equal importance. The prevalence of artificial cranial deformity, spoken of in a previous lecture, causes some difficulty by limiting the number of crania possessing their natural form at our disposal; but still there is sufficient evidence to show great variation in the cephalic index of American skulls. Although such extreme dolichocephaly as is met with among the Eskimo is very rare among true $\Lambda$ mericans, the larger number of crania of Indians, excepting those inhabiting the west coast of North America, and the region west of the Andes in South America (Pcru and Bolivia), as well as Patagonia, in all of which regions brachycephaly prevails, are either mesaticephalic or moderately dolichocephalic. But the two forms are curiously intermixed, or at all events found in different tribes inhabiting contiguous regions, much, in fact, as they are in Europe. As the inhabitants of the two extreme ends of the continent, the Eskimo and the Fuegians, arc both dolichocephalic (though in the case of the latter the evidence of cranial form is not yet so complete as might be wished), and as certain skulls, apparently of great antiquity, which have been discovered in Patagonia and Brazil are of the same form, it has been conjectured that the primitive inbabitants of the continent were a race with long and narrow heads, and that the brachycephalic race are later intruders.

The characters of the skeleton of the face exhibit, as is so often the case, greater uniformity than those of the cranium proper. The frontal region is almost universally low and retreating, and the supraciliary ridges generally well developed in the males. This and the form of the nose distinguish them from the majority of Asiatic Mongols. Nasal bones, compressed laterally, bollowed near their upper end, and forming a salient projection forwards at the lower end, giving the characteristic high bridge to the nose of the living face, are found in the great majority of American skulls from all parts of the continent. The tendency to a narrow form of nasal aperture (so very marked in the Eskimo) prevails throughout the American continent, the average inclex of 123 specimens being $47^{\circ} 2$, which is

${ }^{1}$ Abstract Report of Prof. Flower's lectures at the Royal College of Surgeons, Narch a to March 19, on the Comparative Anatomy of Nan.
Continied from p. (:. almost as low as that of Europeans, while a really platyrhine nose, such as is the rule among negroes and Australians, is rarely, if ever, met with. The form of the orbit is also characteristic, being almost invariably large, round, and high, having an average index in 129 examples of $91^{\circ} 5$. In the artificially-flattened heads this index is greatly increased, as the depression of the forehead drags the superior margin of the orbit upwards, often so much as to cause the vertical height to exceed the horizontal cliameter. The malar bones are always full, and project laterally, and the nasi-malar angle, though somewhat diminished by the saliency of the nose, approaches to that characteristic of the Mongolian races. In the projection of the jaws forwards the skeleton of the face holds an intermediate position between the orthognathous whitc and the prognathous black races, in a great many cases inclining towards the latter. The lower jaw is large and the chin fairly prominent; the teeth are of moderate size and vertically implanted. Morton found the average cranial capacity of 155 ancient Peruvian skulls to be as low as 75 cubic inches, less than that of almost any other known race. It has been thought that some error may have crept into his method of measurement, but his estimate is probably not far wrong, as the average of 47 male skulls in the College collection is 1,345 cubic centimetres, or 82 inches, and of 50 females, r, 194 c.c., or 73 inches, giving a mean for both sexes of 77 cubic inches. On the other hand the barbarous tribes of Indians of both North and South Amcrica gave, in Morton's hands, an average capacity (for both sexes) of 84 cubic inches, and the Chinooks, from the mouth of the Columbia River, have remarkably capacious skulls, the average of 7 males in the College being 1,589 c.c. (97 inches), larger than those of any other race, but these may be rather exceptional specimens. It is, however, perfectly certain that the crania of the comparatively civilised Peruvians were much smaller than those of either the Indians of the North-West, or the Patagonians, or even Fuegians; but, as Morton remarks, the former, living under a thoroughly organised paternal despotism, seem neither to have thought nor acted except at the dictation of a niaster, while the brain of the savage was always in a state of activity to provide against the necessities and dangers of his daily life. But it must be recollected that the stature of the Peruvians was much less than that of the hunting tribes, and it is also possible that the difference may depend partly upon some general law connecting the size of the brain with the prevailing temperature, as inhabitants of cold regions have usually a larger brain capacity than those who dwell within the tropics.

The general characters of the American cranium are thus rather negative than positive, but on comparing it with the cranium of other races, it will be seen that it has no affinity whatever with that of any of the negroid people, Australians, Melanesians, or true negroes. From these it differs in every essential character, but with the Mongolian cranium it presents many affinities, especially in the form of the orbit, the narrowness of the nose, and the great size and forward projection of the malar bones. It is by the latter character especially that it differs from the European cranium. The prominence of the nasal bones is sometimes the only distinction to be found between American and North Asiatic skulls. Although Mongolian in the general type of face, it never presents such an extreme exaggeration of that type as is to be seen in the Eskimo, from which it can always be readily distinguished. The best argument for the unity of the American race (using the word in a broad sense) is the great difficulty of forming any natural divisions founded upon physical characters. Although certain special modifications prevail in different districts, and the Mongolian resemblance is greatest on the north-western coast, the same form constantly reappears at widely scparated parts of the continent. Skulls from Vancouver's Island, from Peru, 
and from Patagonia, can be shown which are almost undistinguishable from one another, but the materials at hand, at all events in European collections, are not yet sufficient for following out this interesting investigation to a satisfactory conclusion.

Races of Africa.- - Of the great primary divisions of the human species no one is more distinctly characterised than the Negroid race, if under this term we include the whole of the dark-coloured, frizzly-haired people who inhabit considerable portions of the equatorial region of the so-called Old World, from the West Coast of Africa eastward to the middle of the Pacific. The oceanic branches of the group are not at present under consideration, but only those which inhabit the continent of Africa. The physical features of the Ethiopian negroes have remained unchanged since the earliest historic period, as they are depicted in ancient Egyptian drawings much as we see them now, but geographical and geological considerations tend to indicate a much vaster antiquity for the race. The present northern limit of the negro population of Africa, extending from the River Senegal on the west across the continent in a nearly due easterly direction, corresponds with the Ethiopian region of zoologists, characterised by a fauna altogether different from that of the more northern parts of the continent. The cause of this difference is accounted for by the undoubted fact that at a comparatively recent geological epoch the Sahara was covered with sea, and the portion of Africa lying to the south of it was isolated from the great continental track composed of Europe, North Africa, and Asia. The distribution of the races of man so closely coincides with that of the remainder of the fauna that it is natural to suppose that it [must arise from the same cause, and we may thus attribute to the long separation of the races north and south of the Sahara, during the period in which the waters of the Atlantic flowed over it, their strongly opposed physical characteristics. Since the two races have come in contact by the drying up of these waters much intermingling has taken place along the frontier line, but, considering the immense period of this stage of their existence, it is remarkable how little the original geographical boundary has been shifted.

The physical characters of the negro, in his most typical form, as found in the equatorial regions of Africa, have attracted much attention from anatomical anthropologists. In discussing the possible range of differences between different members of the human species the African negro has, on account of his structure being better known than that of any other of the lower races, always been taken as the antithesis of the white man of Europe, and in numerous treatises on the subject the differences between them have often been either exaggerated or softened down, according to the bias of the writer. The black colour of the skin of the negro, due to an increased number of pigment granules in the cells of the epidermis, is proverbial, but very few negroes, if any, are really black. The Joloffs of Senegambia are described as being "jet black," or even "blue black," but various shades of brown, or even yellow, are more common. The iris is dark brown and the conjunctiva yellowish. The hair is always black, except in the not unfrequent case of albinism. Its peculiar character, its flattened elliptical section, and tendency to assume very close spiral coils, giving the general effect commonly called "woolly," or more properly "frizzly," are well known. The division of the negro races into two distinct groups, those in which the hair grows evenly scattered over the scalp (eriocom $)$ and those in which it grows in distinct tufts, with bare intervals between (lophocomi), thaugh often demonstrated to have been based upon fallacious observations, holds its ground with great tenacity, and is still adopted in most treatises on anthropology. The report of a committee of the Paris Anthropological Society on the growth of the hair of a negro in one of the hospitals of that city, published last year in the Bulletin of the Society, ought to set the question at rest for ever.

The features of the negro are so well known as scarcely to need description. Their chief characteristics are, a narrow but rather vertical forehead, small but rather prominent eyes, full cheek bones (intermediate between those of European and Mongolian), flat broad nose, prognathous mouth, with very full and everted lips, often projecting beyond the level of the nose, large white teeth, and a small chin. In stature there is considerable variation, some tribes being equal or even above the average of Europeans, others much smaller, and there is some evidence of the existence of a true race of pygmy negroes in the interior of Africa. Two thousand black soldiers of African descent in the United States of America, carefully measured during the war, gave an average of $66^{\circ} 2 \mathrm{I}$ inches, or nearly one inch below the average of whites $(67,15)$. The difference in the proportions of the different parts of the body in different races have received much attention from anatomists, and comparison between the negro and the standard European is more completely elaborated than that between any other races; but owing to the paucity of skeletons, on which alone perfect accuracy of measurement can be obtained, much still remains to be done. As regards the length of the clavicle, Broca and Pasteau find that this bone is slightly longer in the negro than in the European, that is as compared with the humerus ; but the comparison is not a satisfactory one, the latter bone being, as will be shown, peculiarly short. Compared with the femur, which is a better standard, as its proportionate size to the height is nearly the same in the two races, the clavicle (as far as the materials available permit the comparison) appears to be shorter than in the European, as was shown last year to be the case with the Andaman Islanders. The differences in the form of the scapula have been fully described by Broca and Livon of Paris. All observers agree that the arms of the negro are longer in proportion to the height than are those of Europeans. This is illustrated by the measurements taken in the American war, which show that when standing upright the mean distance between the tips of the fingers and the upper end of the patella was 2.88 inches in the negro, and as much as 5 inches in the white. The legs are also longer in proportion to the height, though to a less extent. The arms, compared to the legs, are slightly shorter than in Europeans. This is caused by the shortness of the humerus, its length as compared with the femur being as 69 to 100 in the negro and 73 to 100 in the European. The radius is longer even as compared with the femur or with the height, and $\dot{a}$ fortiori as compared with the humerus. The humero-radial index is therefore one of the most characteristic distinctions between the two races. In Europeans it averages 74 (the humerus being roo), in negroes 8o. The femoro-tibial index presents a similar but less striking difference, being in Europeans 82, in negroes 85 . Some of these characters, as the humeroradial index, approximate the proportions of the negro to those of lower forms, but others, as the shortness of the humerus and the greater length of the lower limbs as compared with the height, do not do so, and only present signs of divergence from the European standard, but not of inferiority. The other black races agree generally with the typical African negro in such proportions as he differs from the European, and hence these might be used as valuable distinctive characters in the classification of man; but difficulties arise when the negro is compared, not only with the European, but with other races generally held to be distinct. Although very few of them have been measured in sufficient numbers to give reliable averages, the indications already obtained show that in many points the proportions, though they may distinguish the negro from the European, do not separate him from others, which in many respects are most dissimilar. In the humero-radial index, for instance, the Peruvian and 
the Malay (judging by the skeletons in the College Museum) agree with the negro rather than with some other branches of the so-called Mongoloid races, as the Eskimo and the Samoyede. But this is a subject for further observation rather than hasty generalisation.

The difference between the pelvis of the African negro and that of the European has been pointed out by Vrolik and others. It consists mainly in the increase of the antero-posterior diameter as compared with the transverse, expressed by the pelvic index, or ratio between these diameters, the latter being taken as Ioo. In the European male the average index is 80 , in negroes, according to various observers, from 90 to Ioo. As in the proportions of the limbs, many of the Mongoloid races conform in the characters of the pelvis rather with the negro than with the European.

In the cranial characters the distinctions between the negro and the white races are strongly marked. The average capacity of the cerebral cavity is undoubtedly smaller in the former, even in individuals of approximately the same height. It is, however, considerably higher than in the Australian. The difference between the average capacity of English and negro crania in the College Museum is 123 cubic centimetres, between the latter and the Australian 8 o c.c. Broca's totally independent measurements of skulls at Paris give a difference in the former case (Parisians being substituted for English) of 128 c.c., and in the latter of 83 c.c., so that the results are substantially identical. The general form of the cranium is expressed by the cephalic or latitudinal index, or relation of breadth to length, the latter taken as Ioo. The average index of forty-two negroes of various tribes in the College Museum is $73^{\circ} 6$. Of these more than half are between 70 and 75 , or dolichosephalic; less than half are above 75 , or mesaticephalic; but very few are either below 70 or above 80. The average index of eighty-five negroes from the West Coast of Africa, measured by Broca, is $73^{\circ} 4$, and of fiftythree from East Africa, measured by Lederle, is $73^{\circ} 9$. These remarkable agreements with our own measurements show that between 73 an 74 may be fairly taken as a general average of the cephalic index of the African negro, and that he belongs, therefore, to the moderately dolichocephalic races. The height, measured from the basion to the bregma, is almost identical with the breadth, the average of the forty-two College specimens giving 73.5 . The negro skull in these proportions differs greatly from that of the Fiji Islanders previously described. Differences in the position of the foramen magnum, in the angle formed by its plane, with the horizontal of the skull, and in the various facial angles, which have been pointed out as characterising the negro skull as compared with that of the European, can only be explained by means of diagrams. The facial characters are generally eminently characteristic. The forehead, though narrow, is not retreating. The glabella and supra-orbital ridges are sometimes well developed, but more usually this region is smooth and flat. The orbits have a moderate index, $85^{\circ} 5$ (Broca), or 86.3 according to measurements of the College collection. The nose is distinctively platyrhine, the average index being 55 or 56 . The nasal bones are small and flat, their external surfaces directed forwards, the two meeting in front at a very open angle, instead of a narrow one as in Europeans. The lower margin of the nasal aperture is usually rounded off instead of sharp and strongly defined. Equally characteristic is the pro onathism, which is very rarely absent. The measurement from the basion to the middle of the alveolar border is greater than that from the basion to the nasofrontal suture, whereas in Europeans the reverse is almost always the case.

The teeth are regular, well developed, and generally free from caries. The third molars (wisdom teeth) appear to be always in their place before the closure of the basilar suture, whereas among Europeans they are often much later in coming into place. The size of the teeth varies in different races, but hitherto no accurate measurements have been made to express their difference. The length of the molar series, in a straight line between the anterior edge of the first premolar and the posterior edge of the third molar, may be conveniently used to indicate the size of the teeth, and called $d$. This may be compared with the length of the cranio-facial axis, or basi-nasal length (B N), and a dental index formed from $\frac{d \times 100}{\mathrm{~B} \mathrm{~N}}$. This will give at all events a fair approximation to the relative size of the teeth compared with the skull, as the length B N is one of the least liable to variation of any in the cranium. Unfortunately for the investigation, in a large proportion of the crania in Museums the teeth are wholly or partially lost, and a larger number of specimens must be measured than are at present available. The following indices (which must be regarded as provisional) are however of considerable interest. In the first place it must be observed that the teeth of women, though smaller absolutely, are larger relatively to the cranio-facial axis than those of men. For instance, in Europeans the dental index of males is $40^{\circ} 5$, of females $42^{\circ} 0$. In Australians the disproportion is greater still, being $45 \%$ for the males, and 48.4 for the females examined. In the following table males only will be included. Europeans 40.5, Ancient Egyptians $40^{\circ} 8$, Hindoos $41^{\circ} 2$, American Indians $42^{\circ} 5$, Chinese $43^{\circ} 8$, African Negroes 43'9, Andamanese $44^{\circ}$, Fijians $45^{\circ} 4$, Australians $45^{\circ} 7$. It will thus be seen that in the size of the molar teeth the negroes hold an intermediate position between Europeans and Australians, but approaching nearer to the latter. The actual average length of the molar series in European males is 40.8 millimetres, in Africans $45^{\circ} 4$, in Australians 46. The anthropoid apes give a higher index than that of any of the races of man.

(To be continued.)

\section{ON SYSTEMATIC SUN-SPOT PERIODICITY}

$A \mathrm{~T}$ the present moment, when a good deal of attention $A$ is being directed to sun-spots and their possible influences, it may not be amiss to discuss the question of their systematic periodicity.

We have to ask ourselves whether we can by a limited application of labour so disentangle the apparently complicated and capricious phenomena of sun-spots as to exhibit certain well-defined recurring periods, the superposition of which upon each other may ultimately explain the march of these phenomena. It will be apparent that such an analysis of the past is the first and indispensable step towards any prediction for the future. I will now bring before the readers of NATURE the first results of an attempt of this kind. As the subject will be more fully discussed in another place, I will in the meantime mainly exhibit the results obtained, referring as briefly as may be to the method used in procuring them. The method is that which (in conjunction with Mr. Dodgson) I have already brought before the notice of the Solar Physics Committee and of the Royal Society. It has been applied to thirty-six years of sun-spot observations, beginning with 1832 and ending with 1867 . The first portion of these has been derived from the records of Hofrath Schwabe, the second from those of Carrington, while the latter portion has been derived from De la Rue's Kew series. My first object has been to ascertain to what extent these records exhibit indications of certain systematic inequalities having periods not far differing from twenty-four days. I will limit the present communication wholly to this issue.

These thirty-six years have been split up into three series of twelve years each, and treated after the manner 